Burns, M. W., and May, J. R. (1967). Lancet, 1, 354.

Carilli, A. D., Gohd, R. S., and Gordon, W. (1964). New England fournal of Medicine, 270, 123 .

Eadie, M. D., Stott, E. J., and Grist, N. R. (1966). British Medical fournal, 2, 671.

Fisher, M., et al. (1969). British Medical fournal, 4, 187.

Grayston, J. T., et al. (1965). Fournal of the American Medical Association, 191, 369 .
McNamara, M. J., Phillips, I. A., and Williams, O. B. (1969). American Review of Respiratory Diseases, 100, 19

Medical Research Council (1960). British Medical fournal, 2, 1665.

Medical Research Council (1965a). Lancet, 1, 775.

Medical Research Council (1965b). British Medical fournal, 2, 319.

Ross, C. A., et al. (1966). Thorax, 21, 461.

Somerville, R. G (1963). Lancet, 2 1247.

Stenhouse, A. C. (1967). British Medical fournal, 3, 461.

\title{
Creatine Phosphokinase Activity during Lithium Treatment
}

\author{
R. GOSLING， R. J. KERRY， G. OWEN
}

British Medical fournal, 1972, 3, 327-329

Patients and Methods

All patients attending the Northern General Hospital lithium clinic had been previously diagnosed as suffering from manic depressive illness and suitable for treatment with prophylactic lithium. Patients did not receive any other medication and attended the clinic at regular intervals for clinical and biochemical assessment. These patients have been known to one of us (R.J.K.) for up to 10 years and their psychiatric history has been well documented both before and after starting lithium treatment.

Clinicians forwarding sera from their own patients were consulted about the clinical state of the patient and the nature of the illness. They confirmed that the patients were not receiving any other psychotrophic drugs.

\section{SERUM LITHIUM ESTIMATIONS}

\section{Introduction}

The value of lithium in the treatment of mania is established, but its prophylactic use in mania and depression is still a matter of dispute. The natural history of manic depressive illness with its long periods of remission have prompted Blackwell and Shepherd (1968) to question the prophylactic action of lithium. Long symptom-free periods on lithium carbonate may be due either to the prophylactic action of the lithium ion or to a long period of remission in the disease.

Creatine phosphokinase (C.P.K.) activity has been shown to be increased during some acute episodes of psychotic illness (Meltzer, Elkun, and Moline, 1969). We have confirmed these changes in about half of a group of acutely psychotic patients (Gosling, Kerry, Orme, and Owen, 1972).

Since 1964 a special lithium clinic for the supervision of patients considered suitable for treatment with lithium carbonate has been run at this hospital. These patients attend at appropriate intervals for clinical assessment and the estimation of their serum lithium concentration. In addition, a large number of sera are referred from other clinics in the Sheffield region for serum lithium measurement.

In view of the association between psychotic illness and increased C.P.K. activity it was decided to (1) measure the C.P.K. activity in all blood samples taken for serum lithium estimation in our clinic, and (2) to measure the C.P.K. activity in all serum samples referred to us for serum lithium estimation from other clinics. These repeated estimations give us an opportunity of seeing if lithium stabilizes C.P.K. activity as well as mood.

\footnotetext{
Department of Chemical Pathology, Northern General Hospital, Sheffield

R. GOSLING, B.SC., Biochemist

R. J. KERRY. M.R.C.S., L.R.C.P., D.P.M., Consultant Psychiatrist

G. OWEN, M.B., F.R.C.PATH., Consultant Chemical Pathologist
}

Serum lithium concentrations were measured by atomic absorption with an E.E.L. 140 atomic absorption spectrophotometer and a lithium specific lamp. All sera were obtained from venous blood collected in plain glass universal containers. These sera were diluted 1 in 5 with distilled water. They were compared with appropriate standards prepared from a lithium reference standard supplied by the Fisher Corporation.

\section{SERUM CREATINE PHOSPHOKINASE MEASUREMENTS}

The C.P.K. activity at $35^{\circ} \mathrm{C}$ was estimated by linking the C.P.K. catalysed reaction through hexokinase to one involving glucose6-phosphate dehydrogenase and the conversion of nicotinamide adenine dinucleotide phosphate to its reduced form. Glutathione was included within the reaction mixture to "activate" the C.P.K. The increase in optical density at 340 nanometres due to the formation of the reduced nicotinamide adenine dinucleotide phosphate was plotted by using an L.K.B. 8600 reaction rate analyser and is directly proportional to the C.P.K. activity.

To ascertain the effect, if any, of the lithium ion on the estimation of C.P.K. pooled human serum with raised C.P.K. activity was divided into two portions. One portion was seeded with lithium carbonate to establish a prophylactic serum lithium concentration of $2 \mathrm{mEq} / \mathrm{l}$. Comparison between the seeded and non-seeded sera showed that a prophylactic lithium concentration does not interfere with the estimation of C.P.K.

The reagents used were supplied by the Boehringer Corporation in the form of a test kit for C.P.K. determination (Cat. No. 15926. TCAF). Solutions were prepared as recommended by Boehringer and the reaction was started by the automatic addition by the L.K.B. 8600 of $75 \mu$ l of creatine phosphate, solution 3 of the assay system. For all the solutions only half the recommended test quantities were used because the L.K.B. 
8600 requires a minimum total volume of only $1 \mathrm{ml}$ in each test cuvette.

Normal ranges were established on a group of 72 healthy volunteers and found to be 10 to $60 \mathrm{mU} / \mathrm{ml}$ for females and 10 to $105 \mathrm{mU} / \mathrm{ml}$ for males.

\section{Results}

Out of the 13 female and four male patients attending our lithium clinic three of the females have been found to have occasional peaks of raised C.P.K. activity while remaining clinically well.

Two patients (Cases 1 and 2) had raised C.P.K. activity both before and after starting lithium therapy. Case 3 started on lithium eight years ago, at a time before C.P.K. was studied in these patients.

CASE 1

The patient, a married woman, was first admitted to hospital suffering from mania in 1963 at the age of 49 years. Her previous personality was described as happy and gay although she was easily upset by social injustice. She was also said to have suffered from periods of nervous debility during the previous 12 years. The first attack of mania lasted about five weeks and was relieved by electric convulsion therapy (E.C.T.) and chlorpromazine. She had further attacks of mania, each lasting about five weeks, in 1964, 1965, 1967, and 1969. Since 1970 she has been admitted to hospital four times with similar attacks of mania (Fig. 1). During her last manic illness in December 1970 she started treatment on lithium carbonate. She has subsequently remained well and has attended the lithium clinic regularly. During this time she has shown persistently raised C.P.K. activity with peaks (Fig. 1) which are similar to those associated with her psychotic attacks before starting lithium carbonate.

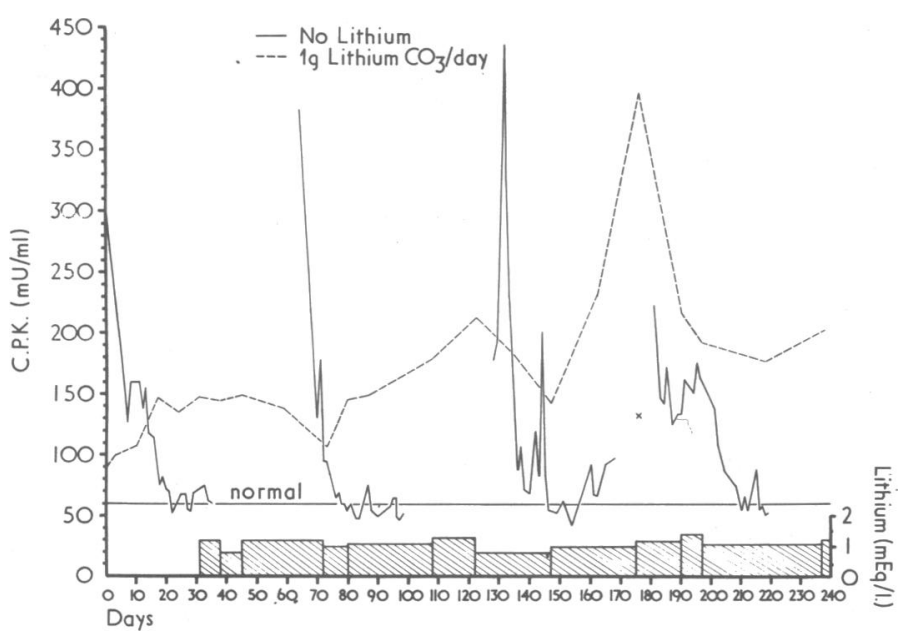
FIG. 1-Case 1 . Creatinine phosphokinase changes before and during lithium
treatment. $X$ shows the C.P.R. activity as an outpatient before starting treatment.

CASE 2

The patient, a married woman, was first admitted to hospital in 1956 at the age of 45 suffering from depression with a history of having been treated for depression as an outpatient a year previously. She was described as being a normally happy person and a good mixer. This first illness lasted about six weeks and was treated with E.C.T. She was next admitted to hospital in 1957 suffering from an attack of mania which lasted for about one month and was treated with chlorpromazine. Since then she has been admitted to hospital with attacks of mania, twice in 1959, twice in 1960, once each year in 1962, 1966, 1968,
1970, and 1971. During her last admission she started prophylactic lithium carbonate. She attended the clinic regularly since her discharge from hospital and has remained clinically well. Fig. 2 shows that she has had grossly raised C.P.K. activity associated with an acute psychotic event. Since starting lithium carbonate she has had two episodes of high serum C.P.K. activity while remaining clinically well. During 1970, before starting lithium, she attended the outpatient clinic and her C.P.K. activity was substantially normal for 165 days. Her C.P.K. activity can be seen to rise as an outpatient (Fig. $2 \mathrm{X}$ ), when not on lithium, before her admission for a manic disorder.

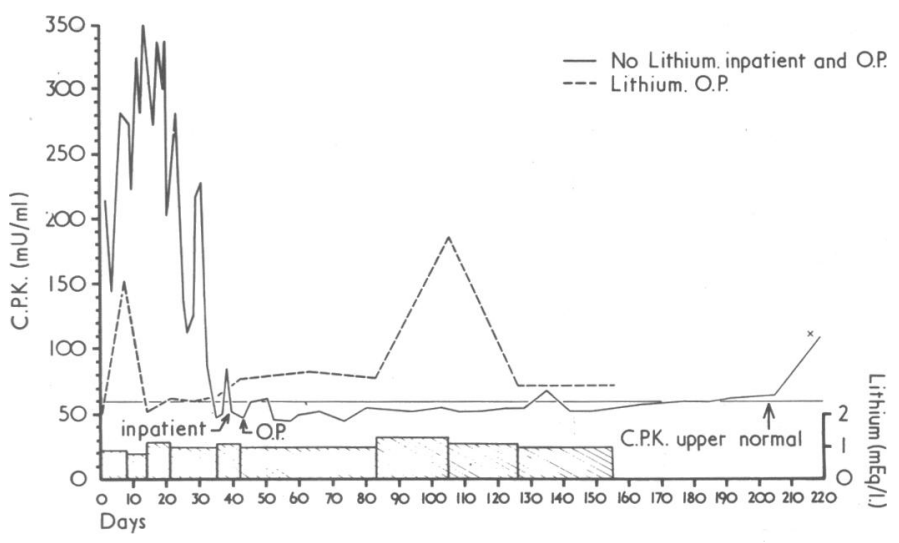

FIG. 2-Case 2. Creatine phosphokinase changes before and during lithium treatment. The last serum C.P.K. as an inpatient and the first as an outpatient (O.P) are indicated $X$ shows the final C P.K activity as an outpatient, not on lithium, before her last admission in mania.

\section{CASE 3}

The patient, a married woman, was first admitted to hospital with depression in 1955. Her husband described her as usually happy and carefree but emotional. This first attack of depression lasted about four weeks and E.C.T. was not given. She had two further depressive illnesses in 1955 and 1956, each of which was treated with E.C.T. and lasted about four weeks. In 1956 she was in hospital again for six months and was treated with sedative drugs only. During this time she had two depressive and manic phases alternating with each other, each lasting about four weeks. Between 1954 and 1964 she had 10 admissions to hospital, with eight depressive and two manic episodes. In 1963-4 she was treated for eight months as an outpatient. She had a regular cycle of hypomania and depression, each episode lasting 24 to 37 days. In June 1964 she was started on lithium carbonate and has remained well. The dose of lithium carbonate has usually been $1 \mathrm{~g}$ a day to maintain her blood level within an acceptable prophylactic range. As seen in Fig. 3 her C.P.K. activity showed marked variations at her different attendances at the clinic.

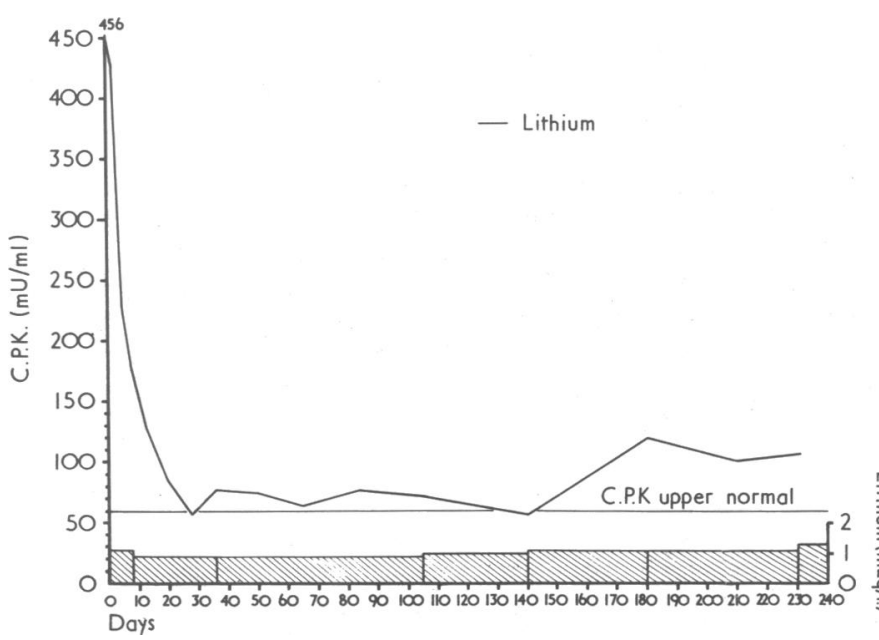

FIG. 3-Case 3. Creatine phosphokinase changes during the eighth year on lithium treatment. 


\section{COMMENT}

The details of C.P.K. activity are shown in Fig. 1, 2, and 3. The serum lithium levels for each patient are within acceptable limits (Fry and Marks, 1971).

Six male and nine female patients under the continuous care of other clinicians were also found to have large increases in C.P.K. activity at a time when they were clinically well and had acceptable serum lithium levels. We received blood at intervals varying from two weeks to two months for serum lithium estimation from 140 patients, 91 of whom were female. In all cases when seen at subsequent interviews the patients were found to have been clinically well at the time of raised C.P.K. activity.

\section{Discussion}

Large increases in C.P.K. activity have been shown to occur in many patients suffering from psychotic illness (Meltzer et al., 1969; Gosling et al., 1972). The raised activity of serum C.P.K. lasts for three to four days after an acute episode of cell necrosis -for example, myocardial infarction (Warburton, Bernstein, and Wright, 1965). The increase in C.P.K. occurs early in the psychotic episode and its median duration is 10 days (Meltzer et al., 1969). This is consistent with continued release of the enzyme into the serum. The increase in serum C.P.K. can precede the psychological manifestations of the illness by a few days (Fig. $1 \mathrm{X}$, Fig. $2 \mathrm{X}$ ). For these reasons the times of increased C.P.K. activity are easily missed in patients who may attend an outpatient clinic at infrequent intervals. We regard a raised serum C.P.K. (in the absence of physical illness) as indicative of either an impending or an established psychotic episode (Gosling et al., 1972).

Long symptom-free periods while taking lithium carbonate may be due either to a long period of remission or to the prophylactic action of the lithium ion. The routine estimation of C.P.K. levels at the time of lithium estimation has shown that lithium does not prevent the increased C.P.K. activity in those patients who have been shown clinically to be lithium responders. These raised levels of C.P.K. activity in patients responding to prophylactic lithium suggest that the basic mechanism of the illness is still present despite the clinically normal mood. In Cases 1 and 2 it is seen that before starting lithium carbonate psychotic illness requiring admission to hospital was always associated with raised C.P.K. activity. Similar increases in C.P.K. activity since starting lithium were not accompanied by mood changes and these might have corresponded to times when the patients would have had psychotic illnesses. The other patient (Case 3), who had been well on prophylactic lithium for eight years, still has peaks of C.P.K. activity, probably indicating the continued need to take lithium carbonate. It will be noted that in these three patients the C.P.K. level, while on lithium, was always at or slightly above the upper limit of normal. We are unable to account for this phenomenon since it has not been observed in the other patients attending the lithium clinic.

Changes in C.P.K. patterns are seen in the sera referred to this laboratory by other clinicians who have reported that the patients are clinically well on lithium therapy. These findings are in agreement with the observations on our own patients.

It is concluded that lithium carbonate controls or prevents manic depressive illness even when the disease remains active as shown by the recurring peaks of raised C.P.K. activity. They also show that lithium carbonate must be continued for long periods as one patient at least is still at risk after being on lithium carbonate for eight years.

We wish to thank Mr. E. Foster and Mrs. J. White for preparing the graphs and Dr. A. J. N. Warrack for helpful criticism.

\section{References}

Blackwell, B., and Shepherd, M. (1968). Lancet, 1, 968.

Fry, D. E., and Marks, V. (1971). Lancet, 1, 886.

Gosling, R., Kerry, R. J., Orme, J. E., and Owen, G. (1972). British fournal

of Psychiatry. In press.
Meltzer, H., Elkun, L., and Moline, R. A. (1969). Archives of General Psychiatry, 21, 731.

Warburton, F. G., Bernstein, A., and Wright, A. C. (1965). British Heart fournal, 27, 740 .

\title{
Chloramphenicol Resistance in the Typhoid Bacillus
}

\author{
E. S. ANDERSON, H. R. SMITH
}

British Medical Fournal, 1972, 3, 329-331

\section{Summary}

Chloramphenicol resistance has been reported in individual strains of Salmonella typhi since 1950, but there had been no accounts of epidemics caused by resistant strains of the organism until 1972, when one occurred in Mexico. Two British patients have been infected in that country, and the organism isolated from them corresponds in all respects with the description of the Mexican epidemic strain of $S$. typhi: it is a degraded Vi strain resistant to chloramphenicol, streptomycin, sulphonamides, and tetracyclines. It owes its resistance to an $R$ factor which can be transferred to Escherichia coli and thence to drugsensitive $S$. typhi. Although there is a negligible risk of

\footnotetext{
Enteric Reference Laboratory, Public Health Laboratory Service,
London N.W.9

E. S. ANDERSON, M.D., F.R.C.PATH., F.R.S., Director

H. R. SMITH, M.A., Member of Scientific Staff
}

\begin{abstract}
dissemination of this strain in Britain the incident is a reminder of the need to restrict the use of drugs such as chloramphenicol to the serious diseases for which they are virtually specific.
\end{abstract}

\section{Introduction}

Chloramphenicol resistance in Salmonella typhi was apparently first reported in England (Colquhoun and Weetch, 1950). It was subsequently observed in India (Murti et al., 1962), West Africa (Njoku-Obi and Njoku-Obi, 1965), and Greece and Israel (Kontomichalou, 1967; Sompolinsky et al., 1967). The resistance in the last two instances was caused by a transferable extrachromosomal element known as a resistance factor or $\mathbf{R}$ factor.

\section{Studies at Enteric Reference Laboratory}

The minimal inhibitory concentration (M.I.C.) of chloramphenicol for drug-sensitive $S$. typhi is between 1 and $3 \mu \mathrm{g} / \mathrm{ml}$ with the technique routinely used in the Enteric Reference Labora- 